\title{
GESTÃO DE RECURSOS NATURAIS: SUSTENTABILIDADE EM PROPRIEDADE PRODUTORA DE SUÍNOS
}

\author{
NATURAL RESOURCE MANAGEMENT: SUSTAINABILITY IN SWINE FARM
}

\author{
Giuliano E. de Souza, Eng. Sanitarista e Ambiental (UFSC) \\ Hugo A. Gosmann, MSc. (UFSC) \\ Paulo Belli Filho, Dr. (UFSC) \\ Rodrigo de A. Mohedano, Dr. (UFSC) \\ Marco Antônio Casarin, MSc. (UFSC) \\ Lucas Benedet, MSc. (UFSC)

\section{Palavras Chave} \\ Sustentabilidade Ambiental; Gestão de Recursos Naturais; Manejo de Dejetos de Suínos
}

\section{Key Words}

Environmental Sustainability; Natural Resources Management; Swine Waste Management

\section{RESUMO}

A suinocultura em Santa Catarina é desenvolvida, principalmente, em pequenas propriedades rurais onde o excesso de dejetos produzidos é um desafio para a sustentabilidade. O presente trabalho apresenta as ações realizadas pelo projeto Tecnologias Sociais para a Gestão da Água (TSGA) para o aumento do índice de sustentabilidade de uma propriedade suinícola localizada no município de Braço do Norte, no sul do estado. Os trabalhos referem-se à aplicação de tecnologias sociais (TS) para o tratamento e valorização dos dejetos e a recuperação de áreas degradadas em faixas de APP. Como resultado, obteve-se a melhoria da qualidade ambiental da propriedade propiciando 100\% de aproveitamento dos dejetos, sem o lançamento de efluentes nos corpos d'água ou contaminação dos solos. Simultaneamente, as tecnologias sociais empregadas geraram subprodutos valoráveis contribuindo com a dimensão econômica, entre eles, o biofertilizante que possibilitou a redução no consumo de fertilizantes químicos, o biogás como fonte de energia renovável e a biomassa de lemnas que foi utilizada como alimento proteico no incremento da produção de peixes gerando uma fonte de renda secundária na propriedade. Conclui-se que as TS aplicadas elevaram o índice de sustentabilidade da propriedade, em suas três dimensões, apresentando grande potencialidade para a replicação na Bacia Hidrográfica.

\section{ABSTRACT}

Swine raising in Santa Catarina is mostly developed in small farms where the excess of waste produced is a challenge for the farm sustainability. This paper presents the actions taken by the project Social Technologies for Water Management (TSGA) to increase the sustainability index of a swine farm located in the county of Braço do Norte, in the southern state. The actions refer to the application of social technologies (ST) for the treatment and recovery of waste and the regeneration of degraded areas in riparian forest. As a result, it was obtained improvement of environmental quality of the property providing $100 \%$ of waste utilization without soil contamination or effluent discharging into water bodies. Simultaneously, the ST employed generated valuable by-products contributing to the economic dimension of sustainability, including the biofertilizer which allowed the reduction in the consumption of chemical fertilizers, biogas as a renewable energy source and biomass of lemnas, that was used as a protein food in the increase of fish production generating a secondary source of income on the property. It was concluded that social technologies applied elevated the property sustainability index in three dimensions, with great potential for replication in the Basin. 


\section{INTRODUÇÃO}

A suinocultura desempenha um papel fundamental na economia catarinense. Com aproximadamente oito mil suinocultores em produção de escala comercial (ASSOCIAÇÃO CATARINENSE DE CRIADORES DE SUÍNOS, 2014) e 6,3 miIhões de cabeças de suínos, segundo levantamento do IBGE (BRASIL, 2013), a atividade é responsável por 21,43\% do PIB de Santa Catarina (ASSOCIAÇÃO CATARINENSE DE CRIADORES DE SUÍNOS, 2014).

Grande parte da produção agropecuária é realizada em pequenas propriedades familiares. De acordo com o último censo agropecuário realizado pelo IBGE em 2006 (BRASIL, 2009), do total de 193.663 estabelecimentos existentes na época, mais de 168 mil foram classificados como estabelecimentos com predomínio total da agricultura familiar, o equivalente $87 \%$ do total de propriedades.

Do ponto de vista ambiental a suinocultura é uma das atividades agropecuárias de maior potencial poluidor em função do volume de dejetos produzidos e do elevado número de contaminantes contidos no efluente. Esses contaminantes, em ação individual ou combinada, representam uma fonte potencial de degradação do ar, dos recursos hídricos e do solo (MIELE, 2006 e OLIVEIRA, 2012).

Os dejetos de suínos possuem alta concentração de matéria orgânica, nutrientes ( $N$, P e K) e patógenos, sendo extremamente poluentes. Se não forem devidamente tratados ou reutilizados os dejetos suínos podem causar degradação dos solos pelo acúmulo de nutrientes, desequilíbrios em ecossistemas aquáticos pela eutrofização, além da emissão de gases do efeito estufa. Esses dejetos se apresentam basicamente na forma de uma mistura de fezes e urina, juntamente a águas de lavagem, resíduos de alimentos (ração), águas de vazamento de bebedouros, águas utilizadas na higienização das instalações e águas de chuva que podem entrar nas calhas (BELLI FILHO, 1995).

O destino final desses dejetos deve ser seu aproveitamento como biofertilizante em lavouras. Segundo Couto (2014), propriedades suinícolas podem utilizar esses dejetos líquidos como única fonte de nutrientes para as culturas ou para complementar a adubação mineral. Em alguns casos, essa prática se torna essencial para o estabelecimento de culturas comerciais.

No entanto, é tolerada uma quantidade máxima de nutrientes assimiláveis pelas plantas e são fixados limites de aplicação, os quais estão previstos em legislação (IN11 da Fundação do Meio Ambiente - FATMA - no caso de Santa Catarina). Caso a utilização do fertilizante orgânico seja feita sem os critérios técnicos adequados, poderá provocar redução na produtividade e impactos negativos ao ambiente, por isso, o uso desses insumos deve sempre estar respaldado por profissional que detenha formação qualificada (CORRÊA et al, 2011). Qualquer excesso de efluente deve ser tratado para se obter condições favoráveis aos padrões de lançamento em corpos hídricos.

Segundo Mohedano (2010), o desenvolvimento e a aplicação de tecnologias que promovam um modelo de produção mais ambientalmente sustentável para a suinocultura são de extrema importância. Se faz necessária a integração da suinocultura nos princípios da Política Nacional dos Recursos Hídricos (lei 9433/97) (BRASIL, 1997) com uma redução significativa no volume de dejetos e gases lançados no ambiente natural, sem comprometer a eficiência econômica da atividade.

É possível reverter o atual quadro de poluição, em benefícios ambientas, utilizando os dejetos como insumo na produção agrícola e na geração de energia elétrica e térmica, além de reduzir o consumo dos recursos naturais e melhorar a qualidade ambiental local.

A aplicação de tecnologias na promoção de uma produção mais ambientalmente sustentável foi o objetivo do projeto Tecnologias Sociais para a Gestão da Água (TSGA) em uma propriedade suinícola de Braço do Norte.

O presente trabalho busca apresentar as ações do projeto para adequação ambiental da propriedade, que conta com sistema de tratamento e valorização de dejetos, com foco na sustentabilidade ambiental da propriedade e gestão de recursos naturais.

\section{REVISÃO BIBLIOGRÁFICA}

\subsection{Tratamento do efluente e aplicação no solo}

A forma mais usual de manejo de dejetos realizada no Brasil é o armazenamento em esterqueiras ou em lagoas para posterior aplicação no solo (GOSMANN, 1997). De acordo com Miranda (2005), a esterqueira serve para o armazenamento dos dejetos, onde será promovida a fermentação da biomassa e redução dos patógenos presentes. Estas são opções de baixo custo para os produtores que possuem áreas de cultivo suficientes, onde esses resíduos possam ser utilizados como fertilizante agrícola orgânico.

Em áreas de cultivo insuficientes, o dejeto excedente deve ser tratado. Várias são as tecnologias de tratamento que podem ser utilizadas na suinocultura. O tratamento biológico é uma excelente alternativa devido ao teor de matéria orgânica encontrado no efluente. Segundo Mohedano (2010), o alto valor da relação DBO/DQO demonstra a elevada biodegradabilidade do dejeto bruto. 
Entre os sistemas de tratamento biológico recomendados está o tratamento anaeróbio em biodigestores seguido de lagoas de estabilização para polimento. O biodigestor (Figura 1) é um reator biológico que degrada a matéria orgânica (biomassa) em condições anaeróbias (ausência de oxigênio), produzindo um efluente líquido (biofertilizante) e gerando o biogás (KUNZ, HIGARASHI e OLIVEIRA, 2005).

Figura 1: Representação esquemática de um biodigestor

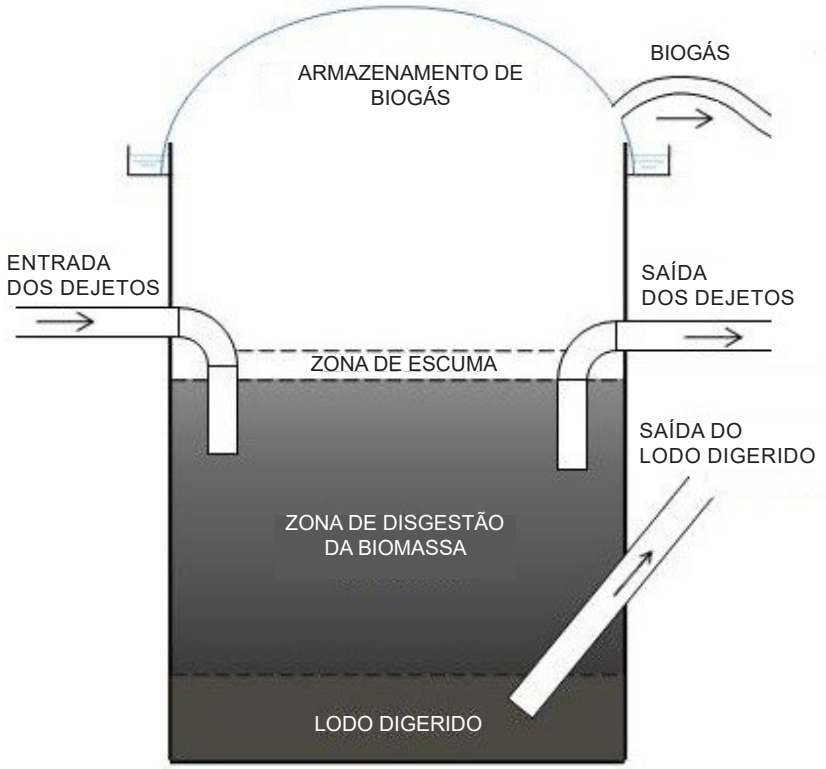

Fonte: Projeto TSGA

\subsubsection{Lagoa de estabilização com macrófita aquá- ticas (Lemnas)}

Entre as diferentes configurações de lagoas de estabilização estão as lagoas de macrófitas lemnáceas (conhecidas popularmente por lemnas ou lentilhas d'água) (Figura 2), que podem ser utilizadas no tratamento de diversos tipos de efluentes orgânicos. No tratamento dos dejetos suínos, as

Figura 2: Exemplo de lagoa de lemnas utilizada para tratamento de dejeto suíno e detalhes da planta aquática da espécie Landoltia punctata

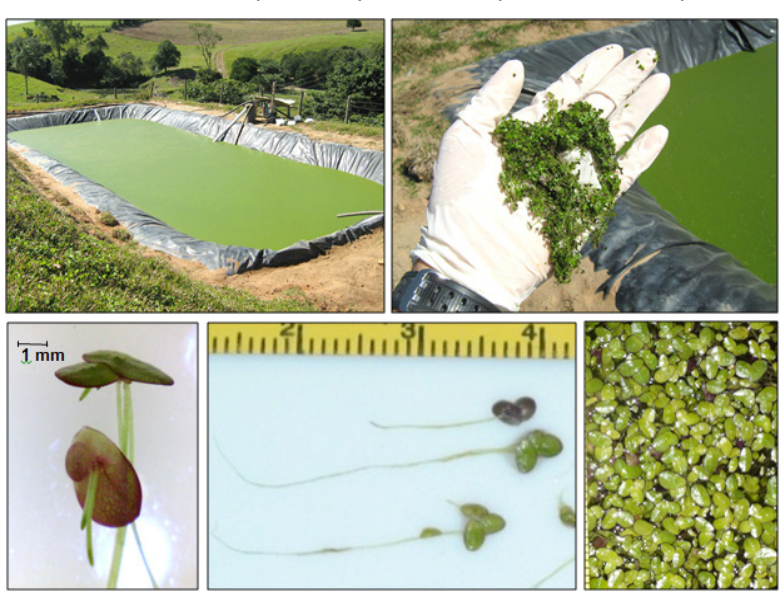

Fonte: Mohedano (2010) macrófitas lemnáceas são utilizadas com sucesso, pois além de promover a remoção de nutrientes ( $\mathrm{NeP}$ ) do efluente, geram uma biomassa com elevado valor nutricional, alcançando mais de 40\% de proteína bruta (IQBAL, 1999). De acordo com Mohedano (2012), essa biomassa pode ser incorporada na dieta de animais como peixes, aves, suínos e bovinos, reduzindo o custo de produção. Pode também ser utilizada como co-substrato no biodigestor para a produção de biogás.

\subsection{Biogás e geração de energia}

O biogás é uma mistura gasosa composta principalmente por gás carbônico $\left(\mathrm{CO}_{2}\right)$ e metano $\left(\mathrm{CH}_{4}\right)$ originado por um processo biológico de decomposição da matéria orgânica por meio de digestão anaeróbia (FRIEHE, WEILAND \& SCHATTAUER, 2010).

Segundo Weiland (2009), a produção de biogás através de digestão anaeróbia oferece significativas vantagens sobre outras formas de produção de bioenergia. A geração de energia através do biogás reduz drasticamente a emissão de GEE - comparada aos combustíveis fósseis - utilizando recursos disponíveis localmente. Além disso, a queima do combustível transforma o metano em dióxido de carbono, o qual é 23 vezes menos poluente em termos de impacto sobre as mudanças climáticas.

Segundo Oliveira (2012), a possibilidade de utilização do biogás para geração de energia térmica e elétrica agrega valor ao dejeto, diminuindo seus custos com tratamento. Os benefícios calculados em sua análise resultam na economia do produtor com a energia que deixa de comprar da concessionária ou na renda obtida com a comercialização da energia gerada na propriedade.

A utilização do biogás produzido aumenta, em média, 45\% a eficiência energética da criação de suínos, pois recupera grande parte da energia da ração ainda presente nos dejetos (ANGONESE, 2006; LIRA, 2009). Porém a baixa eficiência na conversão do biogás em energia elétrica reduz este valor para $8 \%$.

Dal Mago (2009), em estudos de regionalização da produção de biogás, estimou uma produção de 15 milhões de $\mathrm{m}^{3}$ biogás/ano para o município de Braço do Norte, com 9 milhões de $\mathrm{m}^{3} \mathrm{CH} 4$ no mesmo período.

Existem diversos arranjos físicos para a produção de biogás e energia elétrica. Marques (2012), avaliou a produção de biogás e energia elétrica em uma propriedade com 5000 animais em crescimento e terminação. A granja produz em média $550 \mathrm{Nm}^{3} /$ dia de biogás e gera energia durante 10 horas diárias com um motogerador de 76 kW. Apesar da melhora ambiental e energética resultante da utilização do biogás, o autor concluiu nesse caso que o 
investimento não é viável economicamente, pois o custo do kWh produzido foi superior ao pago para a distribuidora.

No sentido de tentar obter viabilidade econômica na produção de biogás e energia elétrica, Coimbra-Araújo et. al. (2014) relataram o estudo de caso do condomínio de agroenergia de agricultores familiares na microbacia da sanga Ajuricaba em Marechal Cândido Rondon/PR. O projeto integra 33 propriedades rurais totalizando um rebanho de 400 vacas e 5000 suínos. Cada propriedade possui seu biodigestor conectado por um gasoduto de $25,5 \mathrm{~km}$ que leva $570 \mathrm{Nm}^{3} /$ dia de biogás até uma micro central termelétrica (MCT). A MCT possui um motogerador de $80 \mathrm{~kW}$ e um secador de grãos com capacidade para 470 sacos. A energia gerada é suficiente para abastecer todos os produtores, reduzindo assim seus custos de produção.

Em abril de 2012 a Agência Nacional de Energia Elétrica (ANEEL) publicou a resolução normativa n` 482 que estabelece as condições gerais para o acesso de microgeração (até 100 kW) e minigeração (100kW a 1 MW) distribuída aos sistemas de distribuição de energia elétrica e o sistema de compensação de energia elétrica. Este sistema permite gerar energia mesmo quando não há demanda na propriedade e armazená-la na rede da distribuidora, evitando assim um possível desperdício de biogás e aumentando a eficiência da conversão do biogás em energia elétrica. Porém fatores como a rede monofásica no campo, limitação da potência instalada nas granjas e a incidência de impostos impedem resultados técnicos e econômicos melhores e ainda inviabilizam os projetos.

\section{PROCEDIMENTOS METODOLÓGICOS}

\subsection{Caracterização da propriedade}

O trabalho foi realizado em uma propriedade suinícola de Braço do Norte, sul do estado de Santa Catarina. A propriedade localiza-se na bacia hidrográfica do Rio Coruja/Bonito, um dos afluentes do Rio Tubarão.

Essa propriedade é considerada pequena, de base familiar, característica representativa da região. Possui uma área total de aproximadamente $24 \mathrm{ha}$, dos quais $15 \mathrm{ha}$ recebem dejetos para adubação de culturas de milho e aveia. O plantel de suínos da propriedade conta com 30 matrizes em ciclo completo (CC) e um rebanho de aproximadamente 300 animais.

\subsection{Ações e estudos realizados}

As ações realizadas pelo projeto TSGA na unidade demonstrativa de Braço do Norte, visaram a implantação de um sistema de produção de suínos com manejo dos dejetos que tornasse a propriedade ambientalmente sustentável.
Os subprodutos gerados no sistema de tratamento foram valorizados dentro da propriedade como insumo no processo de produção ou exterior ao processo, evitando contaminação dos recursos naturais da propriedade e da bacia hidrográfica.

Paralelamente foram realizadas ações de recuperação de áreas de preservação permanente (APP) degradadas.

\subsubsection{Tratamento do efluente}

Tendo como base a unidade de produção de suínos, foram aplicadas tecnologias de manejo, tratamento e utilização dos dejetos, conforme esquema na Figura 3. Coletados na unidade de produção, os dejetos eram transferidos inicialmente para uma central de recolhimento composta por duas caixas de fibra de vidro de $5 \mathrm{~m}^{3}$ cada e, em seguida, bombeadas para o biodigestor (capacidade de $90 \mathrm{~m}^{3}$ ). No biodigestor, os dejetos permaneciam por aproximadamente 30 dias. Este tempo de retenção hidráulica (TRH) permite que a matéria orgânica seja degradada e seja produzido o biogás pelas bactérias metanogênicas. Do biodigestor, os dejetos eram encaminhados para a lagoa de armazenamento $\left(360 \mathrm{~m}^{3}\right.$ de volume e 120 dias de $\mathrm{TRH}$ ) para seu aproveitamento na agricultura (em torno de $70 \%$ ). O excedente seguia para tratamento terciário com lagoas de lemnas.

O sistema contava com duas lagoas de lemnas em série, as quais eram responsáveis pela recuperação de nutrientes (como nitrogênio e fósforo) micronutrientes e metais pesados (como zinco e cobre, no caso da suinocultura), além de promover a inserção de oxigênio no meio líquido e bloquear a passagem de luz na coluna d'água, impedindo o desenvolvimento de algas. Após um tempo de retenção de 102 e 34 dias respectivamente nas lagoas de lemnas 1 e 2, o efluente tratado podia ser reutilizado para fins não nobres (como lavagem da granja) e a biomassa de lemnas - retirada a cada dois dias durante todo o processo - era fornecida como alimento para os peixes criados na propriedade.

\subsubsection{Aplicação de dejetos}

Na propriedade piloto foram feitos alguns estudos relativos à aplicação dos dejetos no solo como biofertilizante, dentre eles: avaliação dos teores de $\mathrm{N}$ total e mineral (por BENEDET et al, 2013); avaliação da dinâmica do carbono e rendimento de culturas em solos submetidos à aplicação de dejetos de suínos e fertilizante nitrogenado mineral (por COUTO, 2010); e estudo de vulnerabilidade do solo à contaminação por fósforo (P) cobre (Cu) e zinco (Zn) (por COUTO, 2014).

A avaliação dos teores de nitrogênio total e mineral foi realizada de acordo com os seguintes tratamentos no solo: 
testemunha sem adubação (T); adubação com dejeto líquido de suínos equivalente a recomendação de N/ha·ano para a cultura do milho e da aveia (DL90) e ao dobro da dose (DL180); adubação com cama sobreposta de suínos equivalente a recomendação de $\mathrm{N} /$ ha.ano para a cultura do milho e da aveia (CS90) e ao dobro da dose (CS180). Foram selecionados blocos ao acaso com três repetições para o delineamento experimental, sendo que cada parcela possui dimensões de 4,5m X6,0m.

As amostras foram coletadas a diferentes profundidades e em seguida foram secas, moídas, peneiradas com malha de $2 \mathrm{~mm}$ e levadas para análises de $\mathrm{N}$ total e mineral.

Valendo-se do mesmo delineamento experimental, o trabalho de Couto (2010) contou com os seguintes tratamentos: (i) testemunha ( $\mathrm{T}$ ); (ii) adubação com cama sobreposta de suínos com a recomendação normal do $\mathrm{N}$ às culturas (CS1) e com o dobro da recomendação (CS2); (iii) adubação com dejeto líquido de suínos com a recomendação normal do $\mathrm{N}$ às culturas (DL1) e com o dobro da recomendação (DL2); e (iv) adubação com fertilizante nitrogenado mineral com a recomendação normal do $\mathrm{N}$ às culturas (AQ1) e com o dobro da recomendação (AQ2).

Já o estudo de vulnerabilidade do solo à contaminação por P, Cu e Zn buscou informações que indicassem o nível de poluição por esses elementos em áreas sob aplicação de dejetos líquidos de suínos (áreas de referência) e posteriormente extrapolou estes dados para as áreas com características ambientais semelhantes.

Primeiramente, o autor realizou um estudo de caso em dez propriedades suinícolas e uma área de floresta sem aplicação de dejetos para entender e descrever os processos ambientais da suinocultura. Nesta etapa, através de dados de perda e cobertura do solo, tempo e quantidade de aplicação de dejetos líquidos de suínos e teores das frações de $\mathrm{P}$, Cu e Zn no solo, estabeleceu a vulnerabilidade utilizando uma análise multicritério.

Após a primeira etapa, foi realizada a extrapolação dos teores de $\mathrm{P}$, Cu e Zn das áreas de referência estabelecidas, e o levantamento das perdas de solo, cobertura do solo e tempo de aplicação de dejetos líquidos de suínos de parte da bacia hidrográfica Rio Coruja/Bonito. A partir de tais dados, e, através de uma análise estatística multicritério, estabeleceu a vulnerabilidade à poluição por P, Cu e Zn da área avaliada.

\subsubsection{Biogás e geração de energia}

Na propriedade, que contava com 30 matrizes em ciclo completo, foi instalado um motogerador de 2,9 kW.

No estudo, foi construída uma rede exclusiva para levar a energia do gerador até a casa do produtor e à maternidade dos suínos. A proposta foi alimentar 4 refrigeradores de 400W na casa do produtor e mais 10 lâmpadas de 100W responsáveis por aquecer os leitões recém-nascidos na maternidade, totalizando $2,6 \mathrm{~kW}$ de carga.

A produção estimada de biogás por matriz foi de 1,15 Nm³ dia o que representa uma produção diária total de $28,75 \mathrm{Nm}^{3}$. Baseado no consumo fornecido pelo fabricante de $2 \mathrm{Nm}^{3} / \mathrm{h}$, o moto-gerador foi instalado para funcionar 14,38 horas por dia.

O calor dos gases de escape do motor foi utilizado para secagem de grãos na unidade de silo secador onde o grupo gerador foi instalado.

Figura 3: Representação esquemática das unidades de tratamento dos dejetos e geração de energia.

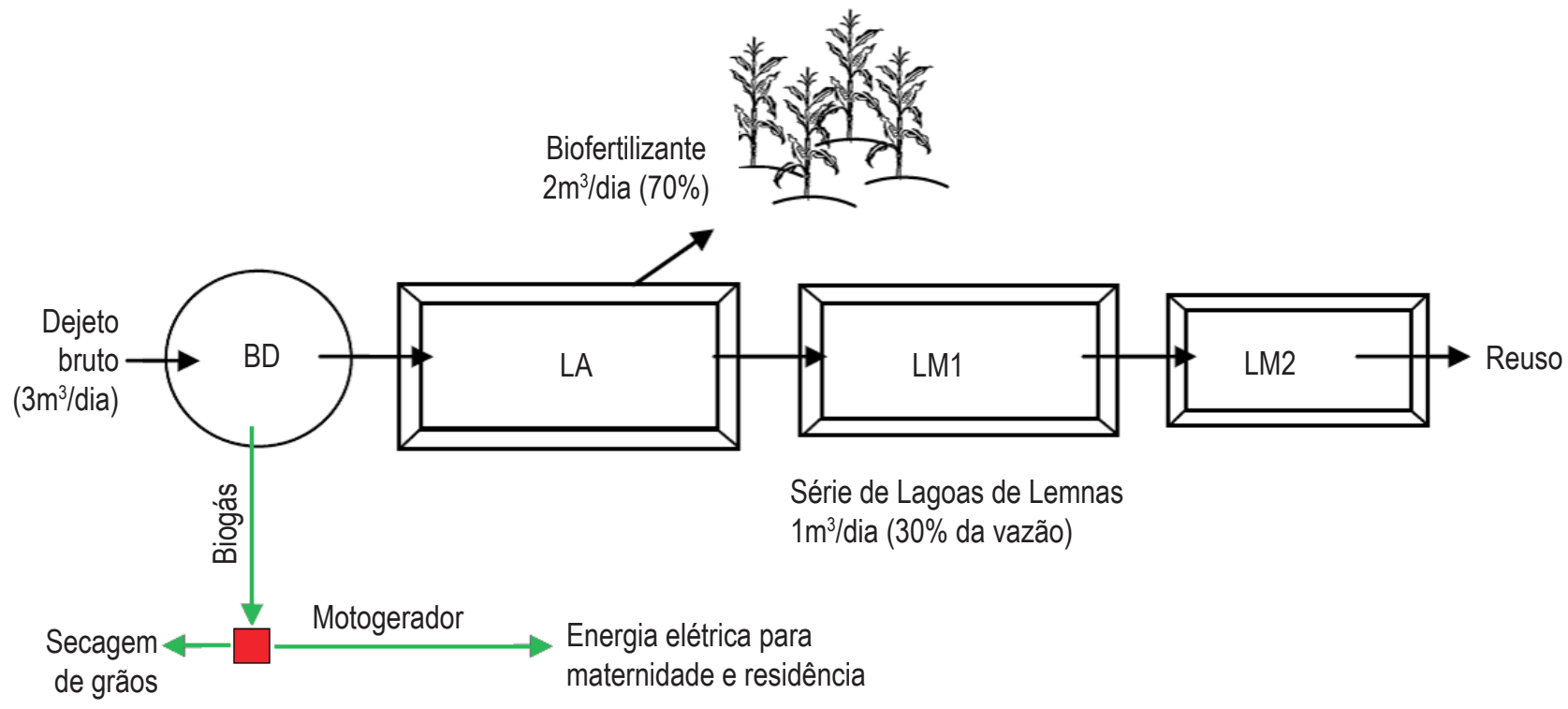




\subsubsection{Recuperação de áreas degradadas}

Com o intuito de adequar a propriedade rural de acordo com as exigências de um Termo de Compromisso de Ajustamento de Conduta assinado pelo proprietário e diminuir os impactos da degradação ambiental, foi desenvolvido o Plano de Recuperação de Área Degradada (PRAD) em APP de Mata Ciliar. A aplicação do PRAD visou recuperar e conservar as zonas ripárias da propriedade, o que fez parte das ações para obtenção da Licença Ambiental de Operação.

Foram selecionadas as faixas determinadas pelo Código Florestal Federal (Lei no 12.651/2012), onde delimitou-se as zonas ripárias próximas aos afloramentos e cursos d'água, considerando-se uma faixa marginal de 30 metros para os açudes e riachos e 50 metros para nascentes. Porém, a recuperação de toda a área aconselhada legalmente para APP, inviabilizaria as atividades agropecuárias na propriedade devido a benfeitorias que, apesar de não respeitarem as distâncias determinadas por lei, eram de difícil realocação. Dessa forma, foram selecionadas áreas para recuperação que conciliassem aspectos relacionados à legislação ambiental, ao meio ambiente $\mathrm{e}$ ecossistemas influenciados pelas matas ciliares e às características de relevo, onde se procurou adaptar o polígono ideal às benfeitorias existentes (Figura 4).

O modelo de recuperação do PRAD considerou a diversidade de espécies e as inter-relações entre plantas e animais. Como método de recuperação foi empregado o plantio de espécies nativas (Floresta Ombrófila Densa e Mista) em conjunto com o controle da regeneração natural de espécies, de acordo com o preconizado pela Instrução Normativa $n^{\circ} 05$ do Ministério do Meio Ambiente.

Foi feita a demarcação e isolamento das áreas a serem recuperadas e realizado o plantio de mudas, visando estimular e acelerar o processo de sucessão natural da APP. Dessa forma, o plantio foi iniciado com as espécies pioneiras, depois as secundárias iniciais, secundárias tardias e por último as climácicas. O modelo de plantio seguido é apresentado na Figura 5.

Figura 5: Modelo de plantio seguido (espaçamento de $3 \mathrm{~m}$ entre linhas e $2 \mathrm{~m}$ entre plantas)

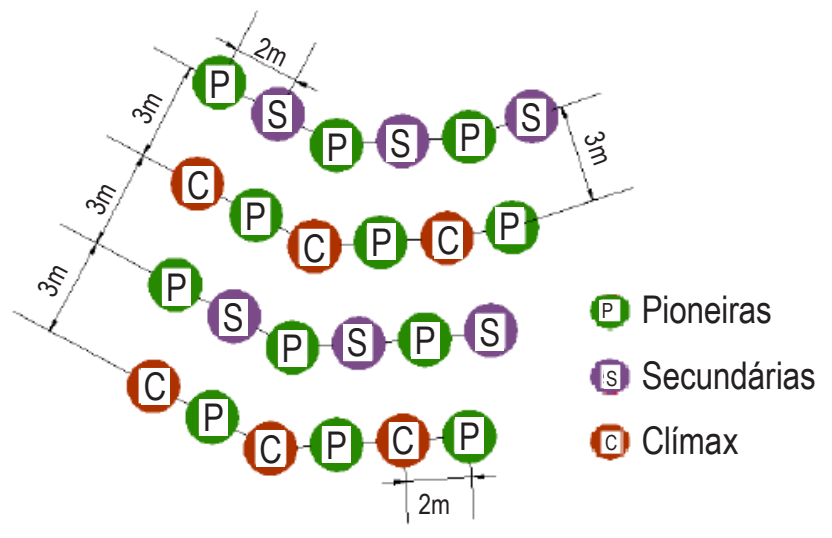

Fonte: Gonçalves (2012)

Figura 4: Áreas de APP e Reserva Legal da propriedade

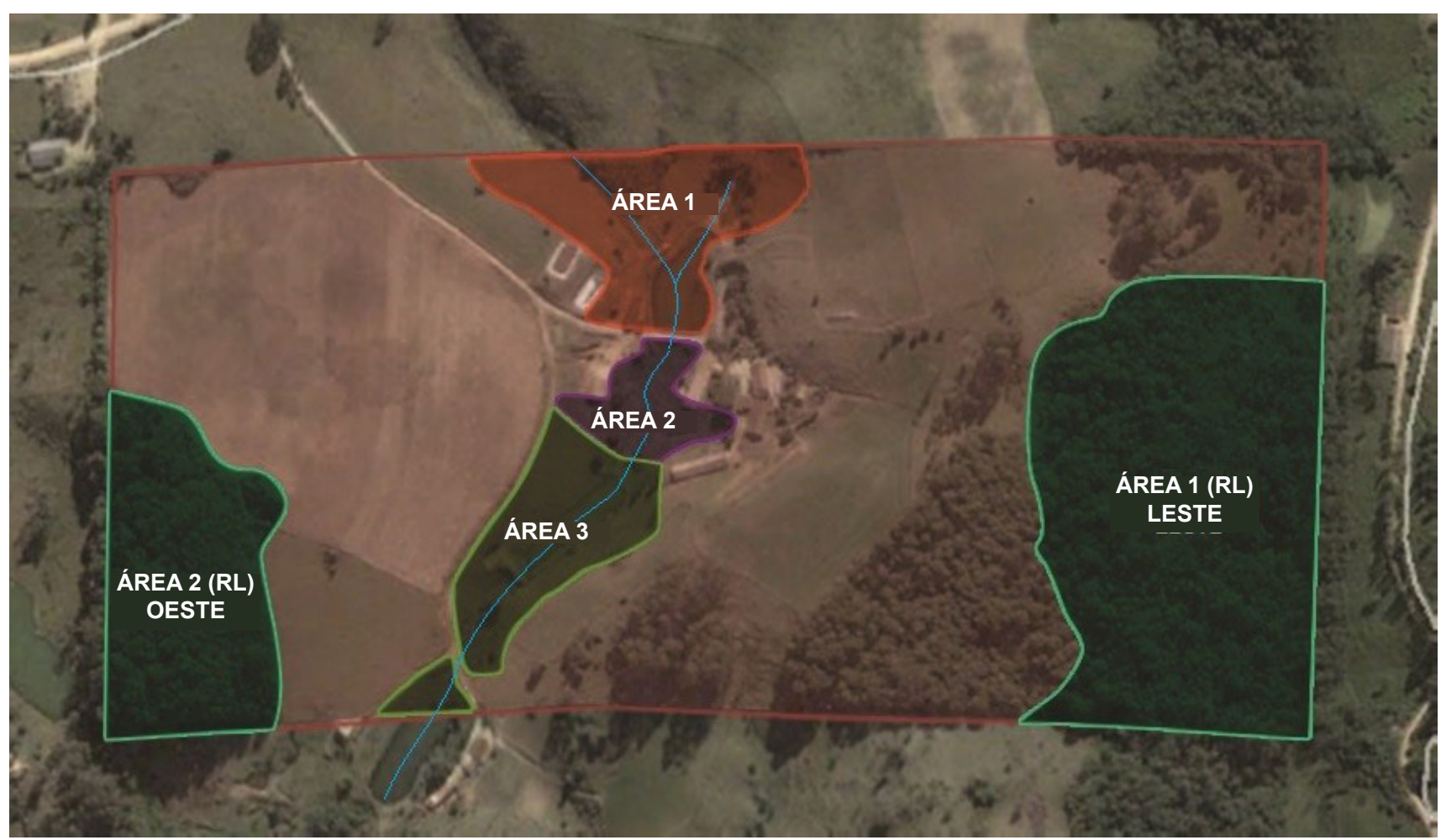




\section{APLICAÇÕES E RESULTADOS}

\subsection{Qualidade da água}

\subsubsection{Tratamento do efluente}

O Sistema de tratamento dos dejetos da propriedade apresentou ótimos resultados na remoção de DBO/DQO e nutrientes. O sistema biodigestor-lagoa de armazenamento apresentou resultados da ordem de $98 \%$ de eficiência na remoção de DQO (HENN, 2005). Já o biodigestor em si, obteve $90,2 \%$ de remoção no inverno e $97,3 \%$ durante o período de verão, devido a maior eficiência das bactérias metanogênicas nas temperaturas mais elevadas do verão (DAL MAGO, 2009). As lagoas de Lemnas, após um ano de monitoramento avaliando-se parâmetros determinados previamente, apresentaram como resultados do polimento do efluente, as seguintes eficiências de remoção: $\mathrm{NTK}=98 \%, \mathrm{~N}-\mathrm{NH} 3=99 \%, \mathrm{Pt}=94 \%, \mathrm{DQO}=96 \%$, $\mathrm{DBO} 5=95 \%, \mathrm{ST}=92 \%$, E. coli $=3 \log$ (MOHEDANO, 2010). A concentração de oxigênio dissolvido no meio líquido, segundo Mohedano (2010) passou de praticamente ausente no efluente bruto para $3,02 \pm 1,2 \mathrm{mg} / \mathrm{L}$ após o tratamento. A eficiência total do sistema foi de $99,9 \%$ na redução de DBO, 6 log na remoção de E. Coli e 99,8\% na remoção de NTK e Pt, deixando o efluente em condições de ser lançado no corpo receptor a jusante ou ser aproveitado na propriedade para fins menos nobres. A biomassa de lemnas produzida durante o tratamento era utilizada como insumo para piscicultura na propriedade elevando a produtividade de tilápias, segundo relato do produtor. Esta biomassa apresentou em média 35\% de proteína bruta (Mohedano et al 2012).

\subsection{Qualidade do solo}

\subsubsection{Aplicação de dejetos}

O resultado obtido pelos autores na avaliação dos teores de $\mathrm{N}$ total e mineral mostrou maiores teores de nitrogênio total (até $15 \mathrm{~cm}$ de profundidade) em solos com aplicação de $180 \mathrm{~kg} \mathrm{~N} /$ ha.ano de cama sobreposta. No tratamento testemunha (sem aplicação de dejetos), foram observados que os maiores teores de $\mathrm{N}$ total estavam até os $10 \mathrm{~cm}$ de profundidade, porém com valores inferiores aos outros tratamentos. Também se observou que a adição dos dejetos não influenciou os teores naturais de $\mathrm{N}$ total a partir dos $15 \mathrm{~cm}$ de profundidade (Figura 6).

Na camada superficial de solo (até $2,5 \mathrm{~cm}$ ), foram obtidas maiores concentrações de $\mathrm{N}$ mineral com o tratamento de dejetos líquidos (180kg N/ha.ano), entretanto, para as camadas mais profundas, foi o tratamento CS180 que apresentou os maiores teores (Figura 7).

De acordo com os resultados obtidos por Couto (2010) no estudo da dinâmica do carbono e rendimento de culturas, tanto a aplicação de dejeto de suíno na forma líquida e sólida, quanto de fertilizante nitrogenado mineral não afetaram o teor de carbono orgânico total no solo e pouco influenciaram a biomassa microbiana. A respiração basal do solo não sofreu influência das doses e dos tipos de adubos testados, assim como estes também não afetaram a decomposição da palhada nem o rendimento da aveia e do milho. Influenciaram apenas nos atributos químicos $\mathrm{pH}, \mathrm{P}, \mathrm{K}, \mathrm{Ca}$ e Mg, sendo que os maiores valores foram obtidos no tratamento com cama sobreposta (CS2).

Quanto aos estudos sobre a vulnerabilidade do solo à contaminação por fósforo (P), cobre (Cu) e zinco (Zn), em Couto (2014), o autor percebeu que as aplicações de dejetos líquidos de suínos aumentaram as frações de Cu e Zn solúvel, trocável, mineral, orgânica e total na camada superficial do solo, no entanto, o Cu e o Zn migraram no perfil do solo nas áreas com mais de 17 anos de aplicação de dejetos.

O Cu é acumulado principalmente na forma orgânica e mineral do solo, e o Zn preferencialmente na forma mineral. O Cu oferece maior risco à poluição das águas superficiais que o $\mathrm{Zn}$, especialmente nas áreas com mais de 17 anos de aplicação de dejetos líquidos de suínos.

$\mathrm{O}$ alto da bacia do Rio Coruja/Bonito apresenta vulnerabilidade a $\mathrm{P}$, $\mathrm{Cu}$ e $\mathrm{Zn}$ predominantemente "Muito Baixa" e "Média", sendo o tipo de cultivo e o tempo de aplicação de dejetos suínos no solo os principais elementos responsáveis pelo resultado.

Figura 6: Quantidades de $\mathrm{N}$ total na camada de $0-60 \mathrm{~cm}$ do solo com e sem aplicação de dejeto líquido e cama sobreposta de suínos

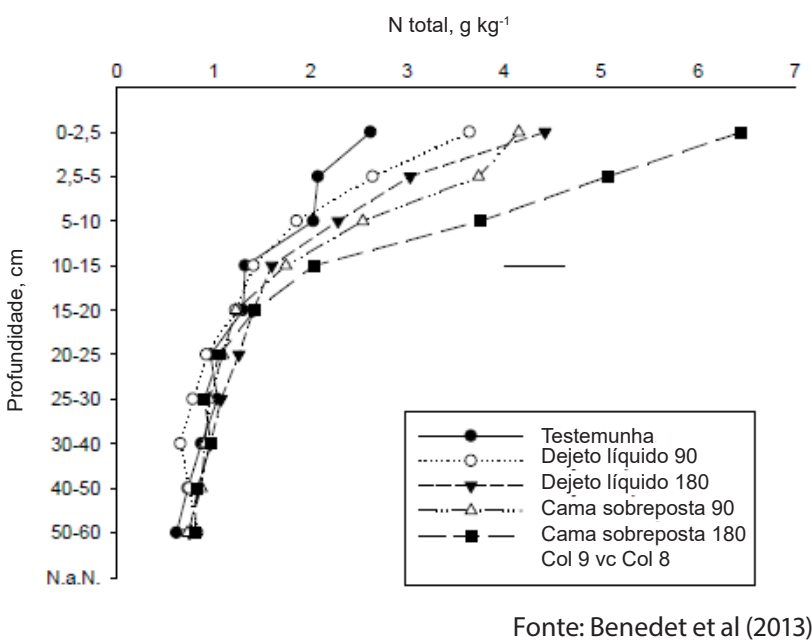

Figura 7: Quantidades de N mineral na camada de $0-60 \mathrm{~cm}$ do solo com e sem aplicação de dejeto líquido e cama sobreposta de suínos 


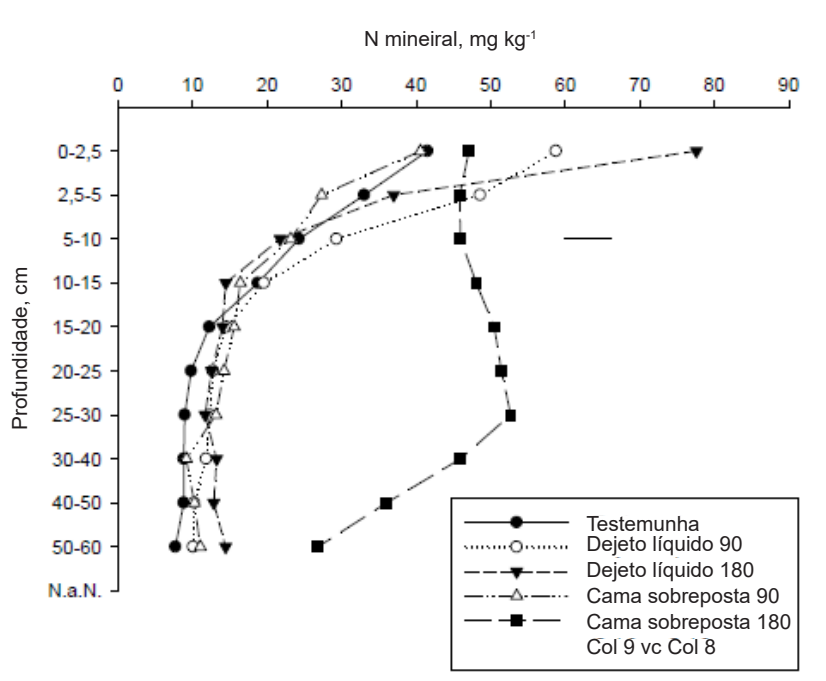

Fonte: Benedet et al (2013)

\subsection{Qualidade do ar}

\subsubsection{Captação de biogás e geração de energia}

Apesar de ter sido projetado para operar por 14 horas diárias, na prática o grupo gerador funcionou de 3 a 4 horas, chegando ao máximo de $12 \mathrm{~h} /$ dia. Este tempo de funcionamento reduzido deveu-se principalmente a menor produção de biogás em dias frios e ao pequeno volume da campânula no biodigestor.

Devido ao moto-gerador utilizado não possuir controle da vazão de biogás, não foi possível obter um funcionamento estável com cargas variáveis. Dessa forma a proposta inicial de alimentar 4 refrigeradores e 10 lâmpadas não foi totalmente bem-sucedida, pois os refrigeradores representam o funcionamento intermitente de cargas indutivas, o que fazia com que o gerador funcionasse em frequências muito abaixo de $60 \mathrm{~Hz}$. Entretanto, com a energia elétrica gerada, foi possível colocar em funcionamento as 10 lâmpadas de uma unidade da granja, o que promoveu uma economia de energia para a propriedade.

Caso o moto-gerador utilizado pudesse ser conectado à rede da distribuidora este poderia ter um desempenho muito superior e produzir uma significativa redução de consumo de energia elétrica sem apresentar os problemas descritos anteriormente, pois a rede torna a operação do motor estável devido ao amortecimento dos picos de carga.

Apesar do sistema conectado apresentar grandes vantagens técnicas em relação a um sistema isolado da rede, não existem atualmente moto-geradores de potência menor que $20 \mathrm{~kW}$ aptos a serem conectados à rede. Além disso, os custos dos geradores existentes e dos equipamentos de conexão e proteção da rede sugerem projetos em granjas com consumo elétrico maior que $8000 \mathrm{kWh} /$ mês (a qual necessitaria 2000 suínos ou 420 matrizes) para serem economicamente viáveis (CASARIN, 2015).

\section{CONSIDERAÇÕES FINAIS}

As atividades implantadas visaram o gerenciamento dos recursos da propriedade, tendo como base a suinocultura, sua principal atividade econômica. Com as unidades de manejo de dejetos implantadas pelo projeto TSGA, foi possível iniciar o processo de consolidação da propriedade como uma unidade modelo de sustentabilidade na suinocultura. No conjunto, os produtos de cada segmento, foram transferidos e aproveitados internamente, diminuindo a necessidade de novos insumos. Como resultado houve uma significativa economia de recursos naturais, a geração de novos produtos e, consequentemente, uma nova fonte de renda para o produtor.

Considerando o estado de Santa Catarina e outras regiões com as mesmas características, o conjunto de atividades desenvolvidas naquela propriedade pode ser difundido e aplicado em outras unidades de produção de suínos. Certamente se estará caminhando para a sustentabilidade dessas granjas, com ganhos financeiros, sociais e ambientais para os agricultores e para a sociedade como um todo.

A implementação do PRAD iniciou-se com a nova fase do projeto TSGA e foi recém finalizado, não havendo, portanto, muitos resultados obtidos em termos de áreas já recuperadas. No entanto, o empenho para a produção mais sustentável e o correto manejo dos dejetos produzidos, assim como a averbação de reserva legal e o plano de recuperação de áreas degradadas possibilitaram a obtenção de licença ambiental e a conformidade da propriedade com a legislação vigente no estado. Dessa forma, esta propriedade tem sido considerada pelo projeto TSGA uma unidade demonstrativa (UD) de tecnologias para o manejo de dejetos e sustentabilidade ambiental.

Apesar da produção de biogás e energia elétrica ser a alternativa ideal para se obter uma suinocultura sustentável, esta tecnologia ainda enfrenta grandes barreiras técnicas, econômicas e políticas. A falta de tecnologia adequada ao tamanho das propriedades da região sul, falta de profissionais qualificados, falta de incentivos para projetos desse tipo, falta de incentivo a fabricantes de equipamentos da cadeia do biogás, inadequação da RN 482 e a incidência de impostos sobre a energia elétrica gerada por meio da micro e minigeração distribuída são algumas dessas barreiras.

\section{REFERÊNCIAS}

ANEEL-Agência Nacional de Energia Elétrica. Resolução

Normativa ANEEL no 48217 de abril de 2012. 
ANGONESE, A. R. et. al. Eficiência energética de sistema de produção de suínos com tratamento dos resíduos em biodigestor. Revista Brasileira de Engenharia Agrícola e Ambiental, v. 10, n. 3, p. 745-750, 2006.

\section{ASSOCIAÇÃO CATARINENSE DE CRIADORES DE SUÍNOS} (Santa Catarina). Relatório Anual 2013. Concórdia: ACCS, 2014. 28 p.

BELLI FILHO, Paulo. Stockage et odeurs des dejections animales: cas du lisier de porc. 1995. $181 \mathrm{f}$. Tese (Doutorado) - Curso de Química Industrial e Ambiental, Université de Rennes I, Rennes. França, 1995.

BENEDET, Lucas; MÜLLER JR, Vilmar; VENTURA, Barbara Santos; LAZZARI, Cleiton Júnior. Ribeiro; SOUZA, Monique; COMIN, Jucinei José. Teores de Nitrogênio Mineral e Total em Solo Submetido a Oito Anos de Aplicações de Dejetos Suínos. In: CONGRESSO BRASILEIRO DE CIÊNCIA DO SOLO, 34ㅇ, 2013, Florianópolis. Anais.... Florianópolis: CBCS, 2013.4p.

BRASIL. Lei 9433 de 08 de janeiro de 1997. Política Nacional dos Recursos Hídricos. 1997.

Lei no 12.651, de 25 de janeiro de 2012.

Código Florestal Federal. Brasília, DF.

BRASIL. IBGE - INSTITUTO BRASILEIRO DE GEOGRAFIA E ESTATÍSTICA. Censo Agropecuário 2006: Agricultura Familiar. Primeiros Resultados. Rio de Janeiro: IBGE, 2009. 265 p.

Produção da Pecuária Municipal, 2013. Rio de Janeiro: IBGE, 2014. 108 p.

CASARIN, Marco. Antônio. Microgeração de energia elétrica a partir do biogás de dejetos suínos. Trabalho não publicado. 2015.

COIMBRA-ARAÚJO, C.H. et al. Brazilian case study for biogas energy: Production of electric power, heat and automotive energy in condominiums of agroenergy. Renewable and Sustainable Energy Reviews, v. 40, p. 826-839, 2014.

CORRÊA,Juliano Corulli;NICOLOSO, Rodrigo da Silveira;MENEZES, June Faria Scherrer; BENTES, Vinícius de Melo. Critérios Técnicos para Recomendação de Biofertilizante de Origem Animal em Sistemas de Produção Agrícolas e Florestais. Concórdia: Embrapa Suínos e Aves, 2011. 8 p. Comunicado Técnico 486.
COUTO, Rafael da Rosa. Dinâmica do Carbono e Rendimento de Culturas em Solo com Histórico de Aplicação de Dejetos Suínos e Fertilizante Nitrogenado Mineral. 2010. 107 f. Dissertação (Mestrado) - Curso de Agroecossistemas, Universidade Federal de Santa Catarina, Florianópolis, 2010.

. Vulnerabilidade do Solo a Poluição por Fósforo, Cobre e Zinco, em Áreas Sob Aplicação de Dejetos Suínos. 2014. 179 f. Tese (Doutorado) - Curso de Engenharia Ambiental, Universidade Federal de Santa Catarina, Florianópolis, 2014.

DAL MAGO, Anigeli. Avaliação de Biodigestores com o Uso de Dejetos de Suínos em Braço do Norte e em Concórdia. 2009. 152 f. Dissertação (Mestrado) - Curso de Engenharia Ambiental, Centro Tecnológico, Universidade Federal de Santa Catarina, Florianópolis, 2009.

FRIEHE, Jörg; WEILAND, Peter; SCHATTAUER, Alexander. Fundamentos da Fermentação Anaeróbia. In: FNR. FACHAGENTUR NACHWACHSENDE ROHSTOFFE (Alemanha) (Org.). Guia Prático do Biogás: Geração e Utilização. 5. ed. Gülzow: FNR, 2010. Cap. 2. p. 20-30.

FUNDAÇÃO DO MEIO AMBIENTE DE SANTA CATARINA Instrução Normativa no 11 - Suinocultura Florianópolis: FATMA, 2014.

GONÇALVES, Juliane. Licenciamento Ambiental em Propriedades Rurais: Estudo de Caso em Estabelecimento Suinícola em Braço do Norte / SC. 2012. 132 f. TCC (Graduação) - Curso de Engenharia Sanitária e Ambiental, Universidade Federal de Santa Catarina, Florianópolis, 2012.

GOSMANN, Hugo Adolfo. Estudos Comparativos com Bioesterqueira e Esterqueira para Armazenamento e Valorização dos Dejetos deSuínos. 1997.126f.Dissertação (Mestrado) - Engenharia Ambiental, Universidade Federal de Santa Catarina, Florianópolis, 1997.

HENN, Alan. Avaliação de Dois Sistemas de Manejo de Dejetos em Uma Pequena Propriedade Produtora de Suínos - Condição de Partida. 2005. 157 f. Dissertação (Mestrado) - Engenharia Ambiental, Universidade Federal de SC, Florianópolis, 2005.

IQBAL, S. Duckweed Aquaculture. Potentials, Possibilities and Limitations, for Combined Wastewater 
Treatment and Animal Feed Production in Developing Countries. Switzerland. SANDEC report n.6 91pp. mar.1999.

KUNZ, Airton; HIGARASHI, Martha Mayumi; OLIVEIRA, Paulo Armando de. Tecnologias de Manejo e Tratamento de Dejetos de Suínos Estudadas no Brasil. Cadernos de Ciência \& Tecnologia, Brasília, v. 22, n. 3, p.651-665, dez/2005.

LIRA, J. C. U. Análise econômica e balanço energético do biogás em granjas de suíno. $85 \mathrm{p}$. Dissertação (Mestrado em Engenharia Elétrica). Universidade Federal de Goiás. Goiânia, 2009.

MARQUES, C. A. Microgeração de energia elétrica em uma propriedade rural utilizando biogás como fonte primária de energia elétrica. 2012. 81p. Dissertação (Mestrado em Energia na Agricultura). Universidade Estadual do Oeste do Paraná - UNIOESTE. Cascavel, 2012.

MIELE, Marcelo. Contratos, Especialização, Escala de Produção e Potencial Poluidor na Suinocultura de Santa Catarina. Tese (Doutorado). UFRGS. Porto Alegre. 2006.

MIRANDA, Cláudio Rocha de. Avaliação de Estratégias para Sustentabilidade da Suinocultura. 2005. 264 f. Tese (Doutorado) - Curso de Engenharia Ambiental, Universidade

Federal de Santa Catarina, Florianópolis, 2005.

MOHEDANO, Rodrigo de Almeida. Uso de Macrófitas Lemnáceas (Landoltia punctata) no Polimento e Valorização do Efluente de Suinocultura e na Fixação de Carbono. 2010. 270 f. Tese (Doutorado) - Pós Graduação em Engenharia Ambiental, Universidade Federal de Santa Catarina, Florianópolis, 2010.

MOHEDANO, R. A., VELHO, V. F., COSTA, R. H. R., HOFMANN, S. M. \& BELLI FILHO, P. 2012 Nutrient recovery from swine waste and protein biomass production using duckweed ponds (Landoltia punctata): Southern Brazil. Water Science and Technology 65 (11), 2042-2048

OLIVEIRA, Paulo Armando Victória de. Produção de Suínosem Sistemas Sustentáveis. In:II ANISUS-CONGRESSO BRASILEIRO DE PRODUÇÃO ANIMAL SUSTENTÁVEL. 2012. Anais... . Chapecó: ANISUS, 2012. p. 57 - 70.

WEILAND, Peter. Biogas Production: Current State and Perspectives. Applied Microbiology and Biotechnology, [s.l.], v. 85, n.4, p.849-860, 24 set. 2009.DOI: 10.1007/s00253-009-2246-7. 